\title{
Ataques filibusteros en contra de México y Canadá durante el siglo XIX: un estudio comparativo
}

\author{
Lawrence Douglas Taylor Hansen \\ EL COLEGIO DE LA FRON'TERA NORTE
}

\begin{abstract}
Se analizan y comparan los movimientos filibusteros que tuvieron lugar en México y Canadá a lo largo del siglo $\mathrm{XIX}$, atendiendo de manera especial esta última región.
\end{abstract}

$\mathrm{D}$ urante el periodo de exploración y colonización del nuevo mundo, el término "filibustero", derivado de la palabra holandesa vrijbuiter, se refería a un bucanero o pirata en busca de botín. En Estados Unidos, a partir de la década de 1850 , la palabra empezó a ser usada para denotar una expedición militar ilegal organizada por intereses particulares en un territorio neutral, para fomentar rebeliones en países y regiones. $\mathrm{El}$ término también se refería a los miembros de aquellas expediciones, así como a la nave en que viajaban. ${ }^{1}$

1 Mientras la expedición mantuviera su orga-
Aunque algunos ciudadanos de otros países participaron en tales actividades, Estados Unidos se ganó una reputación como nación filibustera. Desde el fin de la guerra con México (1848) hasta el estallido de la guerra civil estadunidense (1861), varias expediciones filibusteras procedentes de

nización, y simplèmente incorporara un número limitado de reclutas a las fuerzas rebeldes del país atacado, retendría su carácter filibustero; si se aliaba con los insurrectos, perdía ese rasgo. Véase Gaylord, Sword, 1972, p. vI (prefacio). A pesar de su subtítulo, la monografia de Warren trata del papel de los "filibusteros" en la guerra de Independencia mexicana de 1810-1821. Véa. se también Brown, Agents, 1980, p. 3; May, "Young", 1991, p. 857. 
Estados Unidos invadieron Cuba, Méxicoy América Central, para apoyar a las facciones revolucionarias o para conquistar ciertos territorios y establecer gobiernos locales, algunos de los cuales solicitarían eventualmente la anexión de sus países a Estados Unidos-asílo eperaban muchos expansionistas, en particular los sureños. Las más notables de estas expediciones fueron las encabezadas por el venezolano Narciso López para liberar a Cuba del control de los españoles (18491851); las dirigidas a Yucatán, Sonora y Baja California para separarlos de México (1848-1857), y las de William Walker contra Nicaragua (1855-1860). ${ }^{2}$

En general los historiadores de los movimientos filibusteros del siglo XIX han tratado este tipo de conflicto concentrándose en las regiones mencionadas. El filibusterismo fue motivado, aseveran, por el espíritu marcial que permeaba el sur de Estados Unidos, el deseo de sus habitantes de extender la esclavitud a otras regiones, así como las condiciones de desorden y desempleo creadas en California después de la fiebre de oro. No obstante, muchos otros países y territorios también sufrieron ataques de esta naturaleza, como Canadá. Durante las décadas anteriores a la confederación de las colonias de América del norte británica (1867) y algunos años después, Canadá padeció varios intentos de invasión; aun. que a éstos generalmente no se les ha clasificado como empresas filibusteras, tenían algunos elementos que caracterizaban a las expediciones lanzadas contra México durante el mismo periodo.

$$
2 \text { May, ibid. }
$$

El propósito de este trabajo es analizar y comparar los movimientos filibusteros respecto a ambas regiones, con particular atención sobre el caso de Canadá, debido a que ha sido menos estudiado por parte de quienes han tratado este aspecto de la historia continental.

En el caso de Canadá y México, los ataques filibusteros fueron inspirados en parte por el espíritu del Destino Manifiesto y las ambiciones expansionistas prevalecientes en Estados Unidos durante la primera mitád del siglo XIX. Las expediciones dirigidas contra el norte de México en la década de 1850 fueron vistas favorablemente por los estadunidenses que pensaban que su gobierno no había sido suficientemente exigente al negociar el tratado de paz de 1848 como para despojar a México de sus territorios. Se pensaba como Stephen A. Douglas; el senador del estado de Wisconsin, que declaró:

las leyes del progreso que nos han convertido, de unos pocos [ciudadanos], a una nación poderosa, deberían continuar dominando la conducta de una nación y obligarla a seguir el curso de su destino hacia el sur.

El presidente James Buchanan, quien había abogado por la represión del filibusterismo, también apoyaba los propósitos expansionistas de los estadunidenses al aseverar: "Sin duda es el destino de nuestra raza el esparcirse so-bre este continente de América del Norte [...] la ola de inmigrantes afluirá hacia el sur, y nada puede detener su avance." 3

${ }^{3}$ Hope, Militant, 1964, pp. 96-128; Brown, Agents, 1980, pp. 21-33, 423 y 458.

LaWrence Douglas Taylor Hansen 


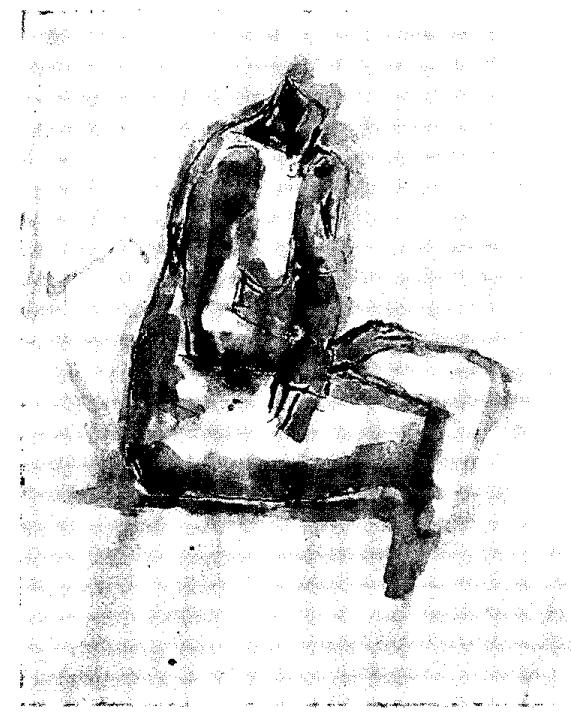

Tales ideas perjudicaron los esfuerzos para hacer más eficaces las leyes sobre la neutralidad promulgadas en 1818, que declaraban ilegales las expediciones filibusteras y establecían fuertes multas contra los transgresores. El filibusterismo provocó debates agrios en el Congreso y el Senado y, como resultado, el gobierno al fin y al cabo adoptó medidas débiles para resolver el problema. Esto fue particularmente cierto en la administración del presidente Franklin B. Pierce (1853. 1855). ${ }^{4}$ Jefferson Davis, secretario de

${ }^{4}$ Proclamas del presidente Franklin Pierce en contra de los ciudadanos que cometen agresiones en territorios centroamericanos, 18 de enero de 1854, 31 de mayo de 1854, y 8 de diciembre de 1855, en Sloan, Franklin Pierce, 1968, pp. 53-55; Nichols, Franklin Pierce, 2a.

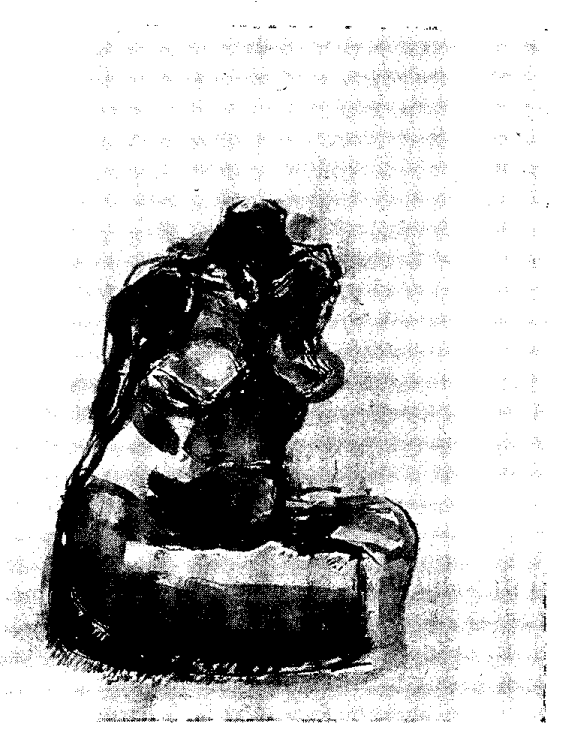

Guerra, por ejemplo, ayudó a reprimir las expediciones contra Cuba durante este periodo y aprobó la táctica adoptada por el general Persifer F. Smith y el capitán Sidney Burbank para interceptar la expedición encabezada por James H. Callahan contra Piedras Negras, en octubre de $1855 .{ }^{5}$ No obstante, en algunos de sus discursos públicos, Jefferson elogiaba las hazañas de William Walker en México y Nicaragua y, en abril de 1854, censuró al general John E. Wool por ser demasia-

ed., 1958, pp. 459-463; Gara, Presidency, 1991, pp. 142-144.

5 Cabe señalar que, al mismo tiempo, la fuerza al mando de Burbank ayudó a cubrir la retirada de Callahan y su banda de México. Shearer, "Callahan", 1951, p. 441; Tyler, "Callahan expedition", 1967 , pp. 579 y $584-585$. 
do activo en sus esfuerzos por evitar que los filibusteros cruzaran a México desde California. ${ }^{6}$

De la misma manera, aunque el ejército estadunidense dedicó una parte sustancial de su tiempo y sus recursos a defender las leyes de neutralidad en las fronteras sury norte, los sentimientos profilibusteros permearon el cuerpo entero de oficiales y soldados rasos durante la época anterior a la guerra civil. Es interesante notar que los ataques filibusteros en contra de México y Canadá ocurrieron en general -aunque había excepciones, como serán señaladas-durante dos conflictos de gran magnitud: en México, en el de la guerra de 1846-1848, y en Canadá, en el de la guerra civil estadunidense. La desmovilización de grandes cantidades de hombres facilitó el reclutamiento de voluntarios. Durante el periodo anterior a la guerra civil, el servicio militar formal y el filibusterismo representaban dos opciones de carreras competitivas. En consecuencia, varios ex oficiales y soldados del ejército estadunidense participaron en ataques filibusteros contra México y Canadá, $o$ colaboraron con tales movimientos. ${ }^{7}$

'También existía cierta simpatía entre el público estadunidense hacia el filibusterismo, lo que complicó los problemas enfrentados por el gobierno y el ejército en sus esfuerzos por reprimirlo. Desde la época colonial, los estadunidenses se habían acostumbrado a recurrir a las armas para apo-

${ }^{6}$ Brown, Agents, 1980, pp. 29-30, 47-48, 118, 209-210, 214, 268 y 423; May, "Young", 1991 , pp. 866,871 y $878-879$.

7 Bell, Old West, 1930, p. 37; May, "Young", 1991, pp. 873-885. yar una causa u otra, en lugar de respetar la voluntad de las autoridades establecidas. Muchos de ellos, especialmente quienes habian pasado su juventud en áreas rurales, acostumbraban el uso del mosquete, del rifle y otras armas pequeñas. No pudieron evitar el ser influidos por los ejemplos de la historia de su país respecto a la conquista y la explotación de pueblos de piel más oscura -indios, negros y mexicanos- en nombre del progreso; tal como los jóvenes de otros países anglosajones habían sido adoctrinados con la idea de que su raza e instituciones eran superiores a las de otros pueblos, lo que justificaba su comportamiento en naciones extranjeras.

El filibusterismo, que aportó a Estados Unidos varios héroes, mártires y villanos, formaba parte de la vida cultural del país durante el periodo anterior a la guerra civil. Los periódicos y las revistas publicaban artículos y editoriales sobre conspiraciones, batallas y juicios relacionados con actividades filibusteras. Había reuniones organizadas para conseguir dinero y reclutas para las expediciones, había desfiles, canciones populares, obras teatrales y conferencias; esto influyó en la mente del público, de manera que el filibusterismo ayudó a definir lo que significaba ser estadunidense. Como un escritor comentó en la revista Harper's Weekly del 10 de enero de 1857, "El espíritu insaciable del filibusterismo [...] constituye una de las virtudes más atractivas de nuestros compatriotas". Aunque algunos estadunidenses se avergonzaban de las depredaciones cometidas por los filibusteros en países extranjeros, muchos expresaron

LaWrence Douglas Taylor Hansen 
su respeto y admiración por el valor mostrado por estos hombres, quienes a menudo luchaban en condiciones muy adversas. ${ }^{8}$

El filibusterismo ejercía una fascinación particular en la población adulta joven de Estados Unidos. Durante las décadas inmediatamente anteriores a la guerra civil, aumentó notablemente esta actividad debido a la llegada de numerosos inmigrantes de muchas naciones europeas, proceso acompañado por una urbanización creciente y una modernización acelerada que, a su vez, provocó considerable inquietud social. Acostumbrados a cambios frecuentes de residencia y ocupación en el ambiente móvil que caracterizaba a la colonización del continente, muchos estadunidenses jóvenes llegaron a considerar al filibusterismo simplemente como otro paso de este proceso. La época en que vivían también era de un idealismo radical. A los jóvenes de las áreas rurales y urbanas, algunos de los cuales habían sido lectores ávidos de las novelas de Sir Walter Scott o de los relatos en torno a los héroes del folclor estadunidense, como Daniel Boone, les gustaba la oportunidad de poder participar en el tipo de aventura que el filibusterismo aparentemente ofrecía. Fue únicamente después, cuando habían experimentado un poco de lo que era la guerra verdadera, que comenzaban a reflexionar sobre el asunto. ${ }^{9}$

Sea como fuere, el filibusterismo, en general, no se caracterizaba por el

${ }^{8}$ Goetzmann, Eagle, 1966 , pp. 74-88; Slotkin, Fatal, 1985, pp. 242-261.

9 May, "Young", 1991, pp. 861-864. idealismo en el sentido político o filosófico de la palabra; sus adeptos, por el contrario, se guiaban por consideraciones personales. En algunos casos los líderes de las expediciones declararon que sus metas consistian en liberar a países dominados por gobiernos tiránicos y corruptos, pero en realidad buscaban el prestigio que una victoria en la guerra podría proporcionarles. Es probable que algunos de los voluntarios reclutados por los dirigentes de las expediciones filibusteras hayan sido motivados por un deseo sincero de ayudar a pueblos en lucha contra la opresión. La mayoría, empero, eran o jóvenes que, como se mencionó, buscaban la aventura, o una mezcla con otros tipos de personas -vagos, desempleados, ladrones, etc.- quienes fueron atraídos por las promesas de pago, raciones y equipo equivalentes a lo que recibía el personal militar estadunidense de aquella época, además de las parcelas de tierra, minas y otras formas de riqueza que les serían entregadas después del término exitoso de la campaña. ${ }^{10}$ Aunque las expediciones filibusteras dirigidas hacia México y Canadá compartieron muchas de las características señaladas, en el caso de éste los ataques se remontaron a la época de la guerra de Independencia estadunidense. Canadá había sido el primer blanco de los expansio-

${ }^{10}$ Brown, Agents, 1980, p. 459; May, "Young", 1991, pp. 863-864. Varios hombres, por ejemplo, que no habian logrado hacerse ricos en los campos auríferos de California, se unieron a las expediciones de filibusteros estadunidenses y franceses que invadieron Sonora y Baja California con este propósito. Morefield, Mexican, 1971, p. 7. 
nistas estadunidenses, cuando los contingentes de soldados estadunidenses invadieron Quebec y Nueva Escocia en 1775-1776, con el fin de incorporar estas dos colonias británicas a la Unión Americana. ${ }^{11}$ El llamado "Plan de los Tratados", adoptado por el Congreso Continental en marzo de 1776 , estableció un acuerdo implícito con el gobierno francés: Estados Unidos controlaría todos los territorios terrestres que lograra conquistar a los británicos. La propuesta fue ratificada por medio del tratado, firmado con el go-

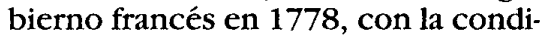
ción de que éste quedara en posesión de cualquier territorio que se lograra conquistar en las Antillas. Aun después de la derrota y del retiro de las fuerzas de invasión estadunidenses en 1775-1776, la esperanza de eventualmente adquirir no sólo Canadá, sino también otras áreas de América del Norte, como Florida, persistía. El gobierno estadunidense hizo otro intento para subyugar a Canadá durante la guerra de 1812-1814 contra Gran Bretaña, que también fracasó. ${ }^{12}$

Canadá era más atractivo para muchos expansionistas, quienes vieron la incorporación de pueblos de diferentes origenes raciales, religiosos y étnicos como un peligro potencial para la sociedad estadunidense. De todos los pueblos del continente americano, los canadienses se asemejaban más

11 Para descripciones detalladas de las operaciones militares de la campaña de $1775-1776$ para conquistar Canadá y Acadia, véase Smith, Struggle, 1907; Kerr, "American", 1936, pp. 433444; Mackay, Safeguarding, 1968, pp. 21-45.

12 Weinberg, Manifest, 1963, p. 19; Brown, Agents, 1980, p. 458. a los estadunidenses en su carácter nacional y su vida política. Durante la década de 1840, el concepto de homogeneidad racial -o una preferencia por la gente de ascendencia anglosajona en lugar de los mestizos hispanoindígenas de Hispanoamérica-, acentuó este sentido de afinidad con los canadienses. A pesar de que un porcentaje de los canadienses era de origen francés, los estadunidenses estaban conscientes del incremento rápido del segmento anglosajón de la población debido a la inmigración de las islas británicas y de Estados Unidos. ${ }^{13}$

El primer movimiento filibustero significativo en Canadá ocurrió en 1837 subsecuente a la rebelión ocurrida en la región denominada Alto Canadá, territorio que coincidia aproximadamente con la parte meridional de la provincia moderna de Ontario. Muchos republicanos simpatizaban con uno de los grupos rebeldes canadienses más radicales, el encabezado por William Lyon Mackenzie, uno de cuyos objetivos era la eliminación del dominio británico en Canadá. A raíz de que en sus discursos públicos los dirigentes del Alto Canadá usaban palabras e ideas parecidas a las empleadas en la época revolucionaria de 1776 1783 , era natural que esta simpatía condujera a esfuerzos para apoyar a Mackenzie y sus seguidores, con la esperanza de que la lucha resultaría en la unión de Canadá y Estados Unidos. ${ }^{14}$

Después de su derrota por las fuerzas británicas en las afueras de York

13 Weinberg, ibid., pp. 355-364.

14 Porter, "Canadian-american", 1926, pp. 13-15.

LaWrence douglas taylor Hansen 
(Toronto) en diciembre de 1837, Mackenzie huyó al lado estadunidense del río Niágara, donde, tras reclutar a 200 hombres, principalmente estadunidenses, comandados por el estadunidense Renesselaer Van Renesselaer, intentó llevar a cabo la lucha para la liberación de Canadá desde bases instaladas en territorio estadunidense. A raíz de la crisis económica iniciada en 1837, había muchos hombres desempleados y deseosos de combatir a lo largo de los canales y ríos de Nueva York y Michigan; esto facilitó bastante la tarea de reclutamiento rebelde. Los jefes insurrectos también ofrecían ciertos incentivos, como una recompensa monetaria y la promesa de una posterior entrega de terrenos en Canadá para quienes se alistaran. Asimismo, el sentido de desarraigo, combinado con el deseo de aventura, se fortalecía con la idea de una cruzada para difundir los principios republicanos por todo el continente. Se pensaba que con Canadá se podía repetir lo logrado en el caso de Texas.

Una vez que sus fuerzas habían crecido suficientemente, un contingente de aproximadamente 1000 hombres ocuparon Navy Island en el río Niágara, de donde recibían un suministro continuo de parque y provisiones proveniente del lado estadunidense a bordo del barco de vapor Carolina. ${ }^{15}$

${ }^{15} \mathrm{Sir}$ Francis Bond Head, gobernador de la provincia de Alta Canadá, a Henry S. Fox, ministro británico en Washington, 8 de enero de 1838, en Richardson, Compilation, 1907, pp. 461-465; Porter, "Canadian-american", 1926, pp. 15.17; Watt, "Case", 1931, pp. 145-146 y 161; Morton, American, 1937, pp. 163-164.
Una parte importante del apoyo popular a la rebelión de MacKenzie en la región Canadá-Estados Unidos provino de una organización secreta conocida como Hunters and Chasers of the Eastern Frontier (Cazadores de la Frontera del Este). Organizado bajo la forma de una logia masónica, el grupo, cuyo propósito declarado era la eliminación del dominio monárquico en América del Norte, tenía durante su apogeo aproximadamente 50000 miembros por toda la frontera, desde Vermont hasta Michigan, pero también había adherentes en Canadá y el sur de Estados Unidos. En Cleveland, en septiembre de 1838, se adoptó un programa activo para la expulsión de los británicos de Canadá. El mes siguiente se estableció un gobierno republicano para Canadá y se eligieron funcionarios para gobernar el nuevo territorio. También se estableció un banco estatal para el financiamiento de operaciones militares por medio de la emisión de papel moneda, y se reclutaron y equiparon hombres para la planeada invasión de Canadá. ${ }^{16}$

La noche del 29 de diciembre de 1837, elementos de la milicia canadiense, al carecer de suficientes fuerzas para desalojar a los rebeldes de su base en Navy Island, lanzaron un tipo

16 Los funcionarios seleccionados fueron: D. Smith, de Cleveland, como presidente; el coronel Williams, de Ohio, como vicepresidente, y el capitán Appleby, antiguo capitán del buque Caroline, como almirante de la flotilla estadunidense del lago Erie. Porter, "Canadian-american", 1926, pp. 19-21; Morton, American, 1937, p. 169; Overman, "Sidelight", 1938, p. 169; Watt, "Case", 1931, p. 161; McInnis, Unguarded, 1942, pp. $152 \cdot 153$. 


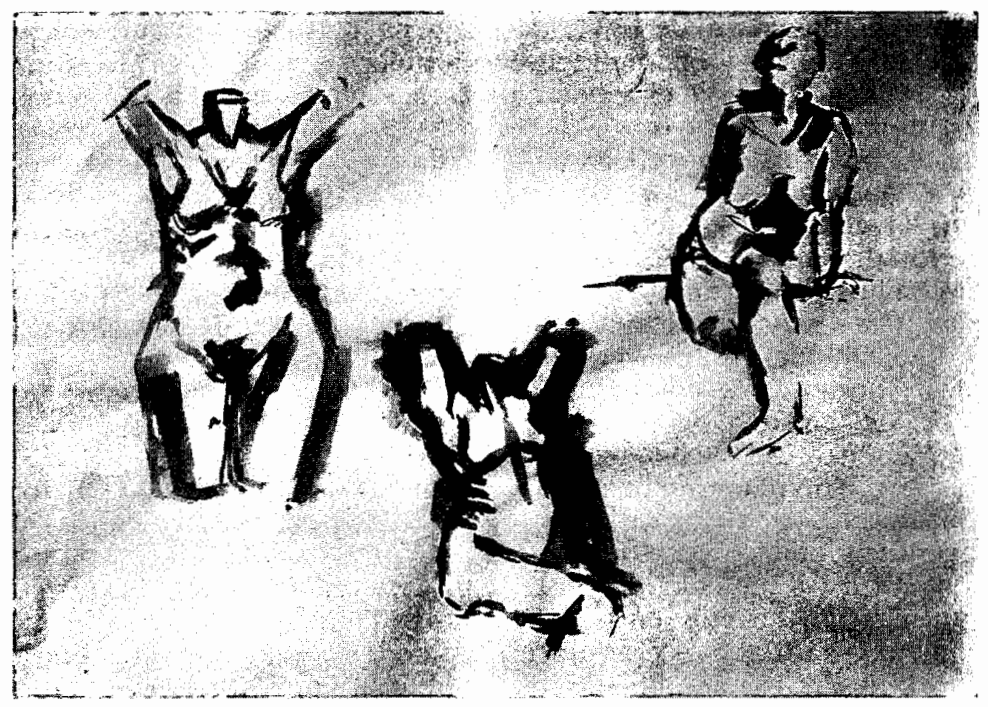

de incursión estilo comando contra el buque Caroline, anclado en la costa de la isla frente al pueblo estadunidense de Schlosser. En el combate mataron a un ciudadano estadunidense (Amos Durfee), y hundieron el barco a dos kilómetros río arriba de la cascada de Niágara. ${ }^{17} \mathrm{El}$ incidente casi provocó una guerra entre ambos países; no obstante, las autoridades federales y estatales estadunidenses, deseosas de

17 Correspondencia intercambiada entre oficiales estadunidenses y británicos sobre la destrucción del buque Caroline, en Richardson, Compilation, 1907, pp. 401-402, 404, 459-465 y 478-479. Véase también Porter, "Canadianamerican", 1926, pp.17-18; Watt, "Case", 1931, pp. 145-146; Morton, American, 1931, pp. 165168; y McInnis, Unguarded, 1931, p. 151; Ireland, "Andrew Drew", 1967, pp. 142-146. preservar la paz, intentaron evitar que ocurrieran ataques contra Canadá provenientes de su territorio. Los gobernadores W. L. Marcy, de Nueva York, yS. H.Jenison, de Vermont, emitieron proclamas que decretaban que los ciudadanos de sus estados deberían observar las leyes de neutralidad referentes a las rebeliones en Canadá. $\mathbf{N}$. Ganon, comisario estadunidense para el Distrito del Norte de Nueva York, viajó a Buffalo, cerca de la frontera canadiense, para levantar actos en contra de aquellos individuos sospechosos de haber violado las leyes federales. ${ }^{18}$

18 N. Ganon al presidente Martin Van Buren, 28 de diciembre de 1837 , en Richardson, Compilation, 1907, pp. 399-400; Watt, "Case", 1931, p. 156. 
En una proclama emitida el 5 de enero de 1838 , el presidente Martin Van Buren admitió que la fuerza rebelde acantonada en Navy Island había sido organizada y pertrechada por Estados Unidos. Ofreció amnistía a todos los estadunidenses unidos a los rebeldes, con la condición de que regresaran pacíficamente a sus casas. Cualquier ciudadano capturado en territorio estadunidense no podría esperar "ningún apoyo o reconocimiento" por parte del gobierno estadunidense. Se hizo un intento para modificar la ley de neutralidad nacional (de 1818) para poder evitar las actividades filibusteras y castigar a quienes participaran en ellas. Asimismo, el general Winfield Scott recibióórdenes para dirigirse sin demora a la frontera para coordinar y fortalecer los esfuerzos gubernamentales en este sentido. ${ }^{19} \mathrm{Al}$ final de cuentas, sin embargo, las autoridades militares tenían la mayor parte del poder necesario para detener los ataques filibusteros, pero estaban limitadas en recursos y capacidad para intervenir. Esto fue particularmente cierto en el caso de los "Cazadores" mencionados, dado que los oficiales de varios estados fronterizos les perdonaron sus actividades, e inclusive, participaron en ellas.

Al quedar separados de su base de abastecimiento, los rebeldes abandonaron su campamento en Navy Island. No obstante, muchos ciudadandos si-

19 Presidente Martin Van Buren al senado y a la cámara de diputados estadunidenses, 5,7 y 8 de enero de 1838; J. R. Poinsett, secretario de Guerra, al general de división Winfield Scott, en Richardson, Compilation, pp. 399, 401, 403, 477 y 481 . guieron apoyando a los insurrectos, quienes realizaron varias incursiones contra Canadá durante $1838 .^{20} \mathrm{El}$ más serio de estos ataques fue el dirigido por un soldado de fortuna llamado Nils Gustaf Von Schoultz y un pirata del río llamado Bill Johnston, cuyos seguidores eran una mezcla de "cazadores" y trabajadores de temporada, varios de los cuales eran estadunidenses. Con cerca de 1000 hombres, Von Shoultz y su grupo cruzaron el río San Lorenzo desde Ogdensburg, Nueva York, en noviembre de 1838, y atacaron al pueblo canadiense de Prescott. Pronto, sin embargo, fueron cercados por fuerzas canadienses más numerosas y obligados a refugiarse en posiciones defensivas que habían preparado alrededor de un molino de piedra, donde resistieron durante una semana, antes de rendirse. ${ }^{21}$ Una fuerza rebelde de aproximadamente 200 hombres conducidos por el autodenominado "general de división" John Ward Birge invadió Canadá por el pueblo de Sandwich, cerca de Windsor, durante la primera semana de diciembre, pero pronto fue derrotado y dispersado por la milicia canadiense. ${ }^{22}$

${ }^{20}$ Overnan, Sidelight, 1938, p. 168; McInnis, Unguarded, 1942, pp. 151-152 y 154-155.

${ }^{21}$ Aunque Von Schoultz supuestamente era polaco, de hecho era finlandés por nacimiento, sueco por naturalización y había pasado sólo seis meses aproximadamente en Polonia. Porter, "Canadian-american", 1926, p. 21; McInnis, Unguarded, 1942, p. 153; Creighton, John A. MacDonald, 1953, pp. 59-68; Collard, Canadian, 1963, pp. 152-156; Sillanpaa, "Death", 1990 , pp. $27 \cdot 31$.

22 Porter, "Canadian-american", 1926, pp. 21-22; Morton, American, 1937, p. 169; McInnis, 
Un movimiento filibustero mucho más grave surgió durante la década de 1860 , cuando una sociedad irlandesa rebelde conocida como la Hermandad Feniana-nombre derivado de una banda de héroes irlandeses legendarios llamados los Fianna-, Ianzó una serie de asaltos contra Canadá. Después de la gran hambruna de 1845 y la rebelión de 1848, millones de irlandeses habían inmigrado a E.U. y Canadá, llevando consigo su enemistad tradicional hacia el dominio inglés sobre Irlanda y su dedicación a la independencia de su país. La Hermandad Feniana, fundada en Nueva York en 1858 con este propósito, descendía de otras sociedades irlandesas-estadunidenses establecidas anteriormente. En 1863, bajo los auspicios de la Hermandad se llevó a cabo una convención en Chicago, que proclamó el establecimiento de la república de Irlanda y la formación de un gobierno nacional. ${ }^{23}$

Unguarded, 1942, pp. 152-153; Douglas, "Battle", 1969, pp. 137-146.

23 Durante muchos años después de que fue establecido, el movimiento fue conocido simplemente como "la organización". James Stephens, su fundador, tuvo como fuente de inspiración las sociedades secretas del continente, por ejemplo, la Sociedad de las Estaciones de Francia, fundada por el socialista francés Auguste Blanqui. Los hombres estuvieron organizados en "círculos", cada uno de los cuales fue dirigido por un "centro", rango equivalente al de "coronel". Los "círculos" estuvieron compuestos de múltiplos de nueve; cada "centro" tenía nueve "Bs." o "capitanes" bajo su dirección; y, bajo la dirección de cada uno de ellos, nueve "Cs." o "sargentos", quienes dirigían los pelotones básicos integrados por nueve hombres o "Ds.", como les llamaban. O'Broin, Fenian, 1971, pp. 1. 8; Neidhardt, Fentanism, 1975, pp. 1-15; O'Broin, "Fenian", 1980, pp. 117-132; Quinlivan y Rose, Fenians, 1982, pp. 1-8.
Aunque la base de las operaciones fenianas se ubicaba en Estados Unidos, sus miembros operaban en otros países y territorios, como Inglaterra, Irlanda, Australia e inclusive las colonias británicas de América del Norte. La meta de la organización feniana de Canadá, establecida en Toronto en 1859 , como en el caso de los grupos fenianos de otras áreas, consistía en intentar, con métodos políticos -y en caso necesario, violentos- obligar al gobierno inglés a otorgar concesiones, así como la independencia total al pueblo irlandés. Aunque muchos irlandeses de Canadá eran activistas políticos, la hermandad tenía pocos adeptos o simpatizantes entre la población local en general. ${ }^{24}$

Los conspiradores fenianos pronto tuvieron marcadas diferencias de opinión respecto a la estrategia general que se debería adoptar. Un grupo se inclinaba a llevar a cabo acciones violentas directamente contra Inglaterra, dentro de Irlanda o Inglaterra. Muchos irlandeses-americanos participaron en tales actos. ${ }^{25}$ No obstante, otro grupo veía a Canadá como el blanco más cercano, así como el mejor lugar desde donde pudieran iniciar la cruzada para la liberación de Irlanda. En caso de que los fenianos se mostraran de-

24 "The orangemen and fenians", hoja volante, Metropolitan Toronto Library, Toronto, Sala Baldwin; D'Arcy McGee, Irish, 1866, pp. 3-45, así comoAccount, 1882, pp. 3-31; Burns, "D'Arcy McGee", 1970, pp. 78 y 86-88; Senior, Last, 1991, pp. 37-39.

25 "Protest of the irish brigade", $40^{\circ}$ congreso, 2a. sesión, House Executive Documentnüm. 157, p. 339; Fentan Raid, 1866, p. 19; Denison, History, 1866, p. 14. 
masiado débiles para conquistar Canadá sin apoyo, podrían, por lo menos, causar que tropa británica adicional fuera asignada a la defensa de América del Norte; esto favorecería la oportunidad de que una rebelión simultánea en Irlanda fuera exitosa. Algunos contemplaban la posibilidad de que sus acciones pudieran conducir a una guerra entre Canadá y Estados Unidos, que resultaría en una campaña de tipo secundario que terminaría en la conquista del territorio por parte de los estadunidenses. ${ }^{26}$

En general, las conspiraciones fenianas contra Canadá se diferenciaban de los ataques filibusteros contra México en que su objetivo fundamental, con ciertas excepciones, era debilitar el control inglés sobre su tierra natal; sin embargo, compartian ciertas características.

Aunque los ataques fenianos contra Canadá no fueron apoyados oficialmente por el gobierno de Estados Unidos, todavía existían muchos estadunidenses que -como en el caso de las incursiones del periodo de 1837 1838-, creían en la doctrina del Destino Manifiesto. William H. Seward, secretario de Estado durante la administración del presidente Abraham Lincoln, y Charles Sumner, el lider republicano del Senado, sostuvieron el punto de vista de Benjamin Franklin de que cualquier división del continente norteamericano era "artificial". En 1866, precisamente un año antes

${ }^{26}$ Denison, History, 1866 , p. 14; McInnis, Unguarded, 1942, pp. 233-234; Warner, Idea, 1960, p. 50; Neidhardt, Fenianism, 1975, pp. 16-23. de la confederación de las colonias británicas de América del Norte, Nathaniel P. Banks, diputado congresional de Massachusetts, presentó al Congreso el borrador de una ley según la cual se permitiría "la admisión [a la Unión] de los estados de Nueva Escocia, Nueva Brunswick, Canadá Este y Canadá Oeste y para la organización de los Territorios de Selkirk, Saskatchewan y Columbia". Banks también redactó el borrador de una ley que reemplazaría las leyes de neutralidad estadunidenses con algunas más débiles basadas en algunos estatutos británicos no muy estrictos. Bajo presión de Banks y otros continentalistas, el Congreso se vio obligado a aprobar una resolución conjunta que recomendaba que el gobierno estadunidense viera el movimiento hacia la unión entre las colonias británicas de América del Norte-que había empezado a tener gran desarrollo a principios de la década de 1860-, "con mucha atención", por la supuesta razón de que constituía una contravención a la Doctrina Monroe. ${ }^{27}$

Varios líderes gubernamentales de Estados Unidos, así como cierto segmento del público estadunidense simpatizaban con el movimiento rebelde. La amarga lucha política ocurrida durante la presidencia de posguerra de Andrew Johnson obligó a que cada grupo político -fuera republicano o demócrata - intentara ganar los votos de los inmigrantes irlandeses. ${ }^{28}$ Aun-

27 Morton, American, 1937 , pp. $299-300$ y 305-306; Stanley, "The 1860's", 1967, p. 45; Cook, Alabama, 1975, p. 37.

28 Morrison y Steel Commager, Growth, 1950 , p. 62. 
que el presidente Andrew Johnson emitió una proclama que advertía a los ciudadanos de Estados Unidos que no deberían participar en movimientos filibusteros, ${ }^{29}$ en varias ocasiones expresó públicamente su simpatía hacia los fenianos. ${ }^{30}$ Ciertos miembros del Congreso también expresaron su simpatía por la causa feniana, y por apoyar el financiamiento de las operaciones de la hermandad. Thomas W. Sweeney, general del ejército estadunidense, aceptó el puesto de ministro de Guerra en el gabinete feniano y comenzó a organizar una fuerza militar. Los jefes fenianos aseguraban que el gobierno estadunidense les había prometido un apoyo eficaz, pero no quisieron divulgar datos precisos sobre su carácter. ${ }^{31}$

29 James Speed, procurador general, a los procuradores de distrito y alguaciles de Estados Unidos, 5 de junio de 1866, transcritos del Daily National Intelligencer, 6 de junio de 1866; Proclama emitida por el presidente Andrew Johnson, 6 de junio de 1866; y el Segundo Mensaje Anual del presidente al Senado, Cámara de Representantes, 3 de diciembre de 1866, en Richardson, Compilation, 1907, pp. 433, 442 y 457-459; Barrie Examiner (edición extra), 7 de junio de 1866.

${ }^{30}$ Durante los primeros meses de 1866 , Bernard Doran Killian, secretario de la Tesoreria de la Hermandad Feniana, supuestamente preguntó al presidente Andrew Johnson por la actitud que su gobierno adoptaría en caso de que un ejército feniano, al actuar conjuntamente con una sublevación de la Hermandad Republicana Irlandesa en Irlanda, conquistara alguna porción del territorio británico situado al norte de Maine y estableciera que el Río San Lorenzo fuera el límite norteño de Estados Unidos. Johnson y su secretario de Estado, William Seward, supuestamente contestaron que el gobierno consideraría tal evento un fait accompli. Davis, "Fenian", 1955, p. 316.

${ }^{31}$ McInnis, Unguarded, 1942, pp. 234-235.
Como en el caso de las expediciones filibusteras contra México, los fenianos se aprovecharon, para reclutar a hombres, de las circunstancias favorables creadas por la desmovilización de miles de veteranos dados de baja de los ejércitos de la Unión. Muchos de estos veteranos eran irlandeses y este hecho, por sí solo, hizo que los líderes fenianos sintieran que el gobierno de posguerra les debía un favor y que no debería intervenir en lo que consideraban su propia causa justa. ${ }^{32}$

Los fenianos también utilizaron el sentimiento antibritánico prevaleciente entre la población del norte de Estados Unidos debido a las actividades de agentes confederados en Canadá durante la guerra civil. Agentes de los estados sureños ubicados alli habían comprado municiones y otras provisiones e inclusive habían lanzado un ataque, en octubre de 1864, contra el pueblo de St. Albans, Vermont. ${ }^{33}$

En vista de los factores señalados, no es sorprendente que el gobierno estadunidense fuera en principio tolerante hacia las acciones de los conspiradores fenianos. Como consecuencia, no se tomó ninguna medida seria para evitar incursiones lanzadas contra Canadá desde Estados Unidos.

32 Davis, "Fenian", 1955, pp. 328-329.

33 Bovey, "Confederate", 1921, pp. 50-51; Morton, American, 1937, pp. 270-294; Burrell, Canadian-american, 1939, pp. 113-158; McInnis, Unguarded, 1942, pp. 220-233; Kinchen, Confederate, 1970 , pp. 35-74 y 104-219. Véanse también las cartas de Clement C. Clay a J. Thompson, 11 de julio de 1864; del teniente Young a Clay, 2 y 20 de septiembre de 1864; y de Clay a Fraser, Trenholm \& Company, 22 de octubre de 1864, en ibid., apéndice, pp. 221, 226-227 y 233. 
Una de las áreas seleccionadas para ser invadidas fue la frontera a lo largo del río St. Croix, entre Maine y Nueva Brunswick. El 10 de abril de 1866, entre 400 y 500 fenianos reclutados en Nueva York fueron agrupados en Eastport bajo el mando del capitán Bernard Doran Killian. No obstante, la invasión no se llevó a cabo debido a que el gobierno colonial de Nueva Brunswick había sido alertado y había tenido tiempo para fortalecer las defensas locales, y también gracias a la captura de un buque que llevaba armas para los fenianos, por parte del guardacostas Ashuelot. Después de la llegada del general de división George Gordon Meade -el comandante victorioso de la batalla de Gettysburg-, a la zona de conflicto, las autoridades militares estadunidenses comenzaron a desarrollar una política mucho más eficaz: patrullar la región fronteriza entre ambos, hacer saber a los fenianos las consecuencias legales en caso de que fueran arrestados bajo la acusación de haber violado las leyes de neutralidad. Los patriotas irlandeses intentaron desembarcar a sus hombres en diversas aldeas ubicadas en el lado canadiense del río St. Croix y, durante un periodo corto, ocuparon Indian Island cerca de Campobello, pero en ambos casos fueron obligados a retirarse debido a la llegada de unidades de la milicia colonial. Los británicos continuaron incrementando sus fuerzas de defensa, $y$ eventualmente establecieron una línea de escaramuzadores de unos 250 $\mathrm{km}$ de largo entre la isla de Campobello y Woodstock, con el resultado de que, para principios de mayo, la mayoría de los llamados "invasores", frustrados en sus intentos por cruzar la frontera, habían abandonado la región fronteriza. ${ }^{34}$

A finales de mayo, una partida de alrededor de 1500 fenianos bajo las órdenes de John O'Neill cruzó el río Niágara y ocupó las ruinas del antiguo Fuerte Erie. De allí, avanzaron a lo largo del río hacia el norte, logrando derrotar a una fuerza de milicia canadiense en Ridgeway; luego tuvieron que retirarse a la frontera debido a la inminente llegada de algunas columnas de tropa regular que estaban convergiendo en aquel punto. Los invasores también sufrieron problemas logísticos, pues un cañonero estadunidense patrullaba el río para evitar que los fenianos recibieran provisiones. Cuando intentaban volver a cruzar el río, algunos patriotas fueron arrestados por soldados estadunidenses del otro lado. Las autoridades estadunidenses locales confiscaron varios de sus escondites de armas y se enviaron tropas adicionales a la frontera. En aquel punto, sin embargo, los esfuerzos estadunidenses por evitar las actividades fenianas cesaron y la mayoría de los voluntarios irlandeses arrestados fueron liberados sin haber sido procesados. La organización feniana no fue disuelta y sus miembros continuaron reuniéndose en convenciones, realizando desfiles en las ciudades estadunidenses y recabando fondos con el propósito de emprender nuevos ataques. ${ }^{35}$

${ }^{34}$ Sir Frederick W. A. Bruce, ministro británico en Washington, D.C., al secretario de Estado William Seward, 13 de julio de 1866, en U.S. Department of State, Papers, 1867, v. 1, p. 245; Vesey, "New", 1939, pp. 198-204; Davis, "Fenian", 1955, pp. 317-332.

35 William A. Seward, secretario de Estado, a 
Para la primavera de 1870 , los fenianos hacían preparativos para la invasión definitiva de Canadá. El primero de esta nueva serie de ataques, dirigido contra los municipios del este de Quebec en mayo de aquel año, terminó en la derrota de la fuerza invasora y el arresto de sus líderes por las autoridades estadunidenses. ${ }^{36}$ Un año y medio más tarde, en octubre de 1871, una expedición de alrededor de $\mathbf{4 0}$ hombres, organizados por William O'Donoghue y John O'Neill, intentaron conquistar la colonia de Red River, Manitoba. Esta fuerza se distinguió de

Charles Francis Adams, embajador estadunidense en Gran Bretaña, 4 de junio de 1866; correspondencia intercambiada entre Seward y sir Frederick W. A. Bruce, ministro británico en Washington, 11, 21, 23 y 30 de junio; 10, 16, 21 y 26 de julio; 4,6 y 9 de agosto; 3 de septiembre; 22 y 27 de octubre; $15,20,26$ y 27 de noviembre de 1866; presidente Andrew Johnson a la Cámara de Representantes, 26 de julio de 1866 , documento anexado a una carta del secretario de Estado Seward a Charles Francis Adams, 30 de julio de 1866; W. Hunter, secretario de Estado suplente, a Adams, 30 de octubre de 1866; Seward a Adams, 17 de noviembre de 1866; en U. S. Department of State, Papers, 1867, v. 1, pp. 126-127, 166-167, 209, 212 y 237-265; Canadá Department of the Secretary of State, Correspondence, 1869, pp. 139-176; The Daily Telegraph (edición extra), Búfalo, N.Y., 14 de junio de 1866; O'Neill, Report, 1870, pp. 37.42; MacDonald, Troublous, 1910, pp. 21-105; Somerville, Narrative, 1866, pp. 14-124; Wheeler, "Reminiscences", 1912, pp. 18-19; Burrell, $\mathrm{Ca}$ nadian-american, 1939, pp. 226-227; McInnis, Unguarded, 1942, pp. 235-237; Senior, Last, 1991, pp. 59-98.

36 Copia de una carta del conde de Granville al gobernador general John Young, 5 de julio de 1870 , William Clowes and Sons, Londres, s.a.; O'Neill, Official, 1870, pp. 3-36; MacDonald, Troublous, 1910, pp. 159-182; Senior, Last,1991, pp. 148-172. los ataques fenianos anteriores por que la meta de sus líderes era la anexión estadunidense de Manitoba y, si fuera posible, de todo el territorio del noroeste, comprado por el gobierno canadiense a la Compañía de la Bahía Hudson en 1869. Varios colonos y comerciantes de Minnesota, motivados por grupos de presión en Washington, habían mostrado cierto interés en este proyecto. Intentaron conseguir la aprobación del presidente Ulysses S. Grant, quien miraba con agrado la idea de que Canadá fuera anexado a la Unión y quien también tenía prejuicios en contra de Gran Bretaña. En mayo de 1871 , empero, Grant dio un viraje y ordenó que fuera publicada una proclama contra los fenianos. Habiendo capturado la factoría de la Compañía de la Bahía de Hudson en Pembina, en la frontera entre Manitoba y Minnesota, los fenianos fueron arrestados por un escuadrón de caballería estadunidense que había cruzado la línea internacional en persecución de los invasores. Éstos habían intentado unirse con el pueblo metis dirigido por Louis Riel, que se había levantado en armas contra el gobierno canadiense de 1869-1870; no obstante, tales planes fracasaron cuando Riel decidió permanecer leal a la corona británica y apoyar a las fuerzas de la milicia para expulsar a los fenianos del territorio canadiense. Con la captura y arresto de los miembros de la expedición O'Donoghue-O'Neill, los intentos de los fenianos de conquistar a Canadá cesaron. ${ }^{37}$

${ }^{37}$ Carta de Warren Cowles, procurador estadunidense para el territorio de Dakota, al 
Los efectos a largo plazo de los ataques filibusteros contra México y Canadá eran semejantes en que fomentaban un espíritu nacionalista en ambos países, así como una antipatía mutua hacia Estados Unidos. En el caso de México, las incursiones acentuaron el odio y la desconfianza contra los estadunidenses, surgidos de conflictos anteriores, como la guerra de Independencia en Texas (1835-1836) y la guerra de 1846-1848. La expedición encabezada por Walker, en particular, complicó las negociaciones entre Estados Unidos y México sobre la compra del territorio de la Mesilla y causó que los políticos mexicanos fueran, de aquel momento en adelante, más precavidos en cuanto a la cesión de tierras a países extranjeros. Tales conflictos con el país vecino, junto

procurador general, George Williams, 28 de enero de 1872, en Moquin, Makers, 1971, p. 8; Perry, "Origin", 1929, pp. 23-40; Morton, American, 1937, pp. 301-302, 304-305, 313-315 y 317-318; Cook, Alabama, 1975, p. 129; Senior, Last, 1991, pp. 173-186. A pesar de que Riel encabezó dos revueltas contra el gobierno canadiense, en 1869.1870 y en 1885 , es posible que haya favorecido la unión de los territorios del oeste con el resto de Canadá con tal de que se satisficieran las demandas del pueblo metis y se asegurara su sobrevivencia como pueblo. En este contexto, su supuesta conexión con los fenianos y los expansionistas estadunidenses podría ser utilizada como herramienta para presionar al gobierno federal de Ottawa para que aceptara sus condiciones. Véanse las minutas registradas por Riel durante la incursión feniana, en De Trémaudan, "Louis Riel", 1923, pp. 133. 143; Warner, "Drang", 1953, pp. 694-712; Gluek, "Riel", 1955, pp. 206-207; Kinsey,Strange, 1965, pp. 190-200. Existían rumores de otros posibles ataques fenianos durante 1884 y 1885 , pero éstos nunca se materializaron. Morton, American, 1937 , p. 393; Warner, Idea, 1960, p. 169. con la intervención francesa de la década de 1860, así como las concesiones favorables a inversionistas extranjeros efectuadas por el gobierno porfiriano, hicieron patente para los mexicanos la necesidad de inculcar la unidad nacional; al mismo tiempo, se desarrollaba entre ellos una fuerte xenofobia que serviría como un potente elemento unificador a las diferentes facciones revolucionarias que surgieron en las décadas siguientes al comienzo de la revolución de 1910.38

En el caso de Canadá, las rebeliones de 1837-1838, junto con los problemas que crearon a lo largo de la frontera con Estados Unidos, resultaron en una investigación británica del problema en torno al aparato gubernamental canadiense, que condujo a la unión del Alto y el Bajo Canadá, un paso importante en el camino a la confederación. ${ }^{39}$

Los ataques fenianos, por su parte, habían aumentado la antipatía hacia los estados norteños estadunidenses surgidos durante la guerra civil. El movimiento que culminó con la unión o confederación de cuatro de las colonias británicas en América del Norte - los Canadás Este y Oeste, Nueva Brunswick y Nueva Escocia-en 1867, se debió, en gran parte, a la respuesta de estas entidades a la amenaza de ser absorbidas por Estados Unidos, y los fenianos fueron vistos como una manifestación de aquella amenaza. Se sentía en Canadá, en general, que los periódicos estadunidenses habían im-

38 Turner, Dtnámica, 1971, pp. 54-65, 7085 y 259-322.

39 Morton, American, 1937, p. 181. 


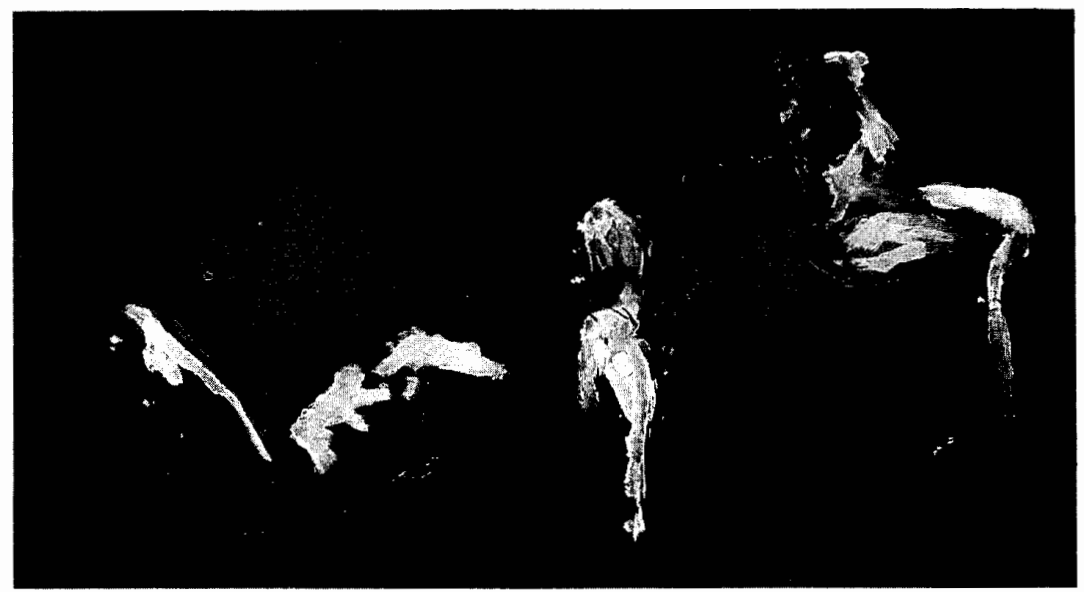

pulsado a los grupos militares irlandeses a llevar a cabo sus actos agresivos contra Canadá, que algunos oficiales y funcionarios inclusive los habían asistido y que los líderes de la nación habían sido algo irresponsables respecto a la vigilancia para evitar las presuntas violaciones a la neutralidad estadunidense. En este sentido, sirvieron para acelerar el desarrollo del sentimiento nacionalista en Canadá y, asimismo, fomentaron la causa de federación en las colonias británicas de América del Norte como un paso obligatorio para adquirir la fuerza que se requería para poder repeler cualquier ataque futuro. ${ }^{40}$ En Nueva

40 Trotter, "Some", pp. 215, 219-226; Stacey, "Fenianism", 1931, p. 255; Keenleysidey Brown,
Brunswick, en particular, los ataques contribuyeron a la convocatoria a una nueva elección, que terminó con la victoria del partido conservador encabezado por Samuel L. Tilley, que favorecía el movimiento hacia la confederación. También fortalecieron la posición de Charles Tupper, primer ministro de Nueva Escocia, quien lideraba este movimiento. En abril de 1866, durante el apogeo del furor por la amenaza feniana a lo largo de la frontera Maine-Nueva Brunswick, la legislatura de Nueva Escocia pasó una resolución

Canada, 1952, pp. 125-126; Creighton, "The 1860's", 1953, pp. 421-422 y 438-444; Stacey, Canada, 1963, pp. 164-165 y 179-203; Burns, "D'Arcy McGee", 1970, p. 77. 
que autorizaba a sus delegados a continuar las negociaciones en torno a la unión de las colonias británicas de América del Norte en Londres. ${ }^{41}$

Las relaciones entre Canadá y Estados Unidos se deterioraron cada vez más después de la confederación (1867). La compra de Alaska por parte del gobierno estadunidense, que Seward calificaba como un "paso visible hacia la ocupación del continente norteamericano entero", fue realizada en parte para fortalecer la influencia de Estados Unidos en la Columbia británica. Seward había propuesto que el gobierno británico cediera territorio a Estados Unidos para arreglar las demandas estadunidenses de una recom. pensa por el hundimiento de barcos mercantes norteños -por corsarios confederados- construidos en Gran Bretaña tales como el Alabama. Sus planes fueron frustrados, sin embargo, con la confederación de las colonias británicas de América del Norte, que estimularon las demandas de que la Columbia Británica fuera unida al resto de Canadá y que fuera construido un ferrocarril para enlazar las provincias del este con la costa del Pacífico. ${ }^{42}$

41 Extracto del Charlotte Advocate, St. Stephens, N. B., reproducido en el New Brunswick Reporter, Fredericton, N. B., 27 de abril de 1866; en Waite, Confederation, 1972, p. 117; Trotter, "Some", p. 226, n. 1; Creighton, John A. MacDonald, 1953, pp. 439-441; Creighton, "The 1860's", 1967, p. 31; Davis, "Fenian", 1955, pp. 331-334; Craig, United States, 1968, p. 146.

42 Morton, American, 1937, pp. 300-301, 306-308 y 315; Keenleyside y Brown, Canada, 1952, pp. 126-136; Stanley, “The 1860's", 1967, pp. 45.46; Dashew, "Story", 1969, pp. 332-337; Jenkins, "British", 1968, pp. 142-144; Cook,
En junio de 1869, dos años después de la confederación, el secretario de Estado Hamilton Fish propuso otra vezal gobiernobritánico, a través de su embajador en Washington, que Canadá cediera ante Estados Unidos como manera de arreglar las reclamaciones de éste sobre el Alabama. Durante los siguientes dos años, Fish reiteró la propuesta y cada vez que lo hizo modificó los términos hasta que, por fin, propuso que el acuerdo, en caso de concretarse, eliminara toda fuente de hostilidad entre ambos países. Respecto a esta propuesta, Sir Edward Thornton, el embajador británico, contestó que aun cuando el gobierno británico estuviera de acuerdo, no accedería sin que Canadá también diera su consentimiento. La contestación de Thornton creó la impresión entre los oficiales del gobierno de que su país ya no podía seguir dependiendo de Gran Bretaña para defenderse de Estados Unidos. El descontento canadiense respecto al gobierno estadunidense creció en 1871 , cuando éste rehusó considerar las reclamaciones de Canadá por los daños sufridos por sus ciudadanos como resultado de los ataques fenianos; también fue dirigido en contra del gobierno británico por existir la percepción de que no se había presionado al gobierno estadunidense sobre este asunto. 43

Alabama, 1975, pp. 45-48; Shi, "Seward's", 1978, pp. 220-238.

43 Morton, American, 1937, pp. 311-322; Stanley, "The 1860's", 1967 p. 46; Dashew, "Story", 1969, pp. 337-348; Cook, Alabama, 1975, p. 159. 
Como en el caso de los ataques filibusteros contra el norte de México, las incursiones fenianas revelaron la necesidad de aumentar $y$ fortalecer la capacidad de los canadienses para defenderse. Excepto la derrota de Ridgeway, los ataques no habían sido una amenaza militar seria; sin embargo, desde el punto de vista psicológico, habían provocado momentos de tensión $y$ angustia entre las comunidades canadienses en las regiones fronterizas. ${ }^{44}$ Por añadidura, a partir de 1864 , preocupado por la situación militar en Europa, conforme aumentaban las tensiones entre Prusia, Austria y Rusia, el gobierno británico había comenzado a retirar sus fuerzas de Canadá. Las administraciones gubernamentales de la segunda mitad de la década de 1860 , bajo la dirección de Lord John Russell y William Ewart Gladstone, creían que con la disminución gradual de las tensiones entre Gran Bretaña y Estados Unidos, el gobierno canadiense debería asumir la responsabilidad de la defensa del país. ${ }^{45}$

En el transcurso de su desarrollo como naciones, Canadáy México compartieron algunas experiencias, especialmente en cuanto a sus relaciones

${ }_{44}$ Thornhill, Between, 1935, pp. 12-14; Vesey, "New", 1939, p. 198.

45 Sin embargo, el gobierno imperial continuó manteniendo a su guarnición en Halifax, Nueva Escocia, así como a una pequeña base naval en Esquimalt, en Columbia Británica, has ta bien entrado el siglo Xx. Stacey, "Fenian", 1936, pp. 276-278; "Britain's", 1955, pp. 187. 198; Lower, Canadians, 1958, p. 279; Stanley, "The 1860's" and "Fighting", 1967, pp. 46 y 764; Craig,United States, 1968, pp. 145-147; Preston, Defense, 1977, pp. 39-43, 46.47, 54-55, 98-99, 146 y $213-314$. con Estados Unidos. Como se comentó, México, América Central y el Caribe no fueron las únicas áreas del continente amenazadas por los esfuerzos expansionistas estadunidenses y las invasiones filibusteras del siglo XIX. Para comprender plenamente el fenómeno del filibusterismo, hay que verlo en un contexto mucho más amplio que los usados hasta ahora; sólo entonces será posible tener una idea más precisa de la verdadera magnitud y significado de este movimiento para los países y territorios afectados.

\section{Bibliografía}

-Bell, Horace, On the Old West coast: being further reminiscences of a major, Grosset Dunlap, Lanier Bartlett, Nueva York, 1930. -Bovey, Wilfred, "Confederate agents in Canada during the american civil war", Canadian Historical Review, vol. 2, núm. 1, marzo de 1921.

-Brown H., Charles, Agents of Manifest Destiny: the lives and times of the filibusters, University of North Carolina Press, Chapel Hill, N.C., 1980.

-Burns, Robin B., "D'Arcy McGee and the fenians: a study of the interaction between irish nationalism and the american environment", en Malcolm Harmon (comp.), Fenians and fenianism: centenary essays, University of Washington, Seattle, Washington, 1970.

-Burrell Shippee, Lester, Canadianamerican relations, 1849-1874, Yale University Press, New Haven, 1939.

-Collard, Edgar Andrew, Canadian yesterdays, Longmans's, Toronto, 1963.

Cook, Adrian, The Alabama claims: american politics and anglo-american relations, Cornell University Press, Ithaca, Nueva York, 1975. 
-Craig, Gerald M., The United States and Canada, Harvard University, Cambridge, Mass., 1968.

-Creighton, Donald, "The 1860's", en J. M. S. Careless y R. Craig Brown (comps.), The canadians, 1867-1967, St. Martin's Press, Nueva York, 1967. ,John A. MacDonald, Houghton Mifflin, Boston, 1953, vol. 1.

-D'Arcy McGee, Thomas, The irish position in british and republican North America: a letter to the editors of the irish press, irrespective of party, 2a. ed., M. Longmoore \& Company, Montreal, 1866. , An account of the attempts to establish fenianism in Montreal, The Post Printing and Publishing Company, Montreal, 1882.

-Dashew, Doris W., "The story of an illusion: the plan to trade the Alabama claims for Canada", Civil War History, vol. 15, núm. 4, invierno de 1969.

-Davis, Harold A., "The fenian raid on New Brunswick", Canadian Historical Review, vol. 36, núm. 4, diciembre de 1955.

-De Trémaudan, A. H., "Louis Riel and the fenian raid of 1871 ", Canadian Historical Review, vol. 4, núm. 2, junio de 1923.

-Denison, George T., History of the fenian raid on fort Erie; with an account of the battle of Ridgeway, Rollo \& Adam, Toronto, 1866.

-Department of State, Papers relating to foreign affairs, 1866, Government Printing Office, Washington, D.C., 1867, vol. 1.

-Department of the Secretary of State of Canada, Correspondence relating to the fenian invasion and the rebellion of the southern states, Hunter Rose and Company, Ottawa, 1869.

-Douglas, Alan R., "The battle of Windsor", Ontario History, vol. 61, núm. 3, septiembre de 1969.
The fenian raid at fort Erie, june the first and second, 1866: with a map of the Niagara peninsula, showing the route of the troops; and a plan of the Lime Ridge battleground, W.C. Chewett, Toronto, 1866.

-Gara,Larry, The presidency of Franklin Pierce, University Press of Kansas, Lawrence, Kan., 1991.

-Gaylord, Harris Warren, The sword was their passport: a history of american filibustering in the mexican revolution, Kennikat Press, Port Washington, Nueva York, 1972.

-Gluek, Alvin C., "The Riel rebellion and canadian-american relations", Canadian Historical Review, vol. 36, septiembre de 1955.

-Goetzmann, William H., When the eagle screamed: the romantic horizon in american diplomacy, 1800-1860, John Wiley \& Sons, Nueva York, 1966.

-Hope Franklin, John, The militant south, 1800-1861, Beacon Press, s.1., 1964.

-Ireland, John, "Andrew Drew: the man who burned the 'Caroline'", Ontario History, vol. 59, núm. 3, septiembre de 1967.

-Jenkins, Brian, "The british government, sirJohn A. Macdonald and the fenian claims", Canadian Historical Review, vol. 49, núm. 2, junio de 1968.

-Keenleyside, Hugh L. y GeraldS. Brown, Canada and the United States: some aspects of theirhistorical relations, Alfred A. Knopf, Nueva York, 1952.

-Kerr, W. B., "The american invasion of Nova Scotia", Canadian Defence Quarterly, vol. 13, núm. 4, julio de 1936.

-Kinchen, Oscar A., Confederate operations in Canada and the north: a littleknown phase of the american civil war, Christopher Publishing House, North Quincy, Mass., 1970.

-Kinsey Howard, Joseph, The strange empire of Louis Riel, Swan Publishing Company, Toronto, 1965. 
-Lower, Arthur R. M., Canadians in the making: a social historyof Canada, Longmans, Green and Company, Toronto, 1958.

-MacDonald, John A., Troublous times in Canada: a history of the fenian raids of 1866 and 1870 , W. S. Johnston \& Company, Toronto, 1910.

-Mackay, Hitsman J., Safeguarding Canada, 1763-1871, University of Toronto Press, Toronto, Ont., 1968.

-May, Robert E., "Young american males and filibustering in the age of Manifest Destiny: the United States army as a cultural mirror", The Journal of American History, vol. 78 , núm. 3, diciembre de 1991.

-McInnis, Edgar W., The unguarded frontier: a history of american-canadian relations, Doubleday, Doran \& Company, Garden City, N. Y., 1942.

-Moquin, Wayne (comp.), Makers of America, Seekers afterwealth, 1871-1890, Encyclopedia Britannica Educational Corporation, 1971.

-Morefield, Richard, The mexican adaptation in american California, 1846 1875 , R. and E. Research Associates, San Francisco, 1971.

-Morrison, Samuel Eliot y Henry Steel Commager, The growth of the american republic, 2a. ed., Oxford University, Nueva York, 1950.

-Morton Callahan, James, American foreign policy in canadian relations, Macmillan, Nueva York, 1937.

-Neidhardt, W. S., Fenianism in North America, Pennsylvania State University, University Park, Penn., 1975.

-Nichols, Roy, Franklin Pierce: young hickory of the granite hills, 2a. ed., University of Pennsylvania Press, Filadelfia, 1958.

-O'Broin, Leon, Fenian fever: an angloamerican dilemma, New York University Press, Nueva York, 1971.

"The Fenian Brotherhood", en David Doyle y Owen Dudley Edwards (comps.), America and Ireland, 17761976: the american identity and the irish connection: Proceedings of the U.S. Bicentennial Conference of Cumaan Merriman Ennis, august, 1976, Greenwood Press, Westport, Conn., 1980.

- O'Neill, John, Official report on the attempt to invade Canada, may 25th, 1870, John J. Foster, Nueva York, 1870. $A$ report of the battle of Ridgeway, Canada West, John J. Foster, Nueva York, 1870.

-Overman, William D., "A sidelight on the Hunters' lodges of 1838 (documentos)", Canadian Historical Review, vol. 19, núm. 2, junio de 1938.

-Perry Pritchett, John, "The origin of the so-called fenian raid on Manitoba in 1871", Canadian Historical Review, vol. 10, núm. 1, marzo de 1929.

-Porter Shortridge, Wilson, "The canadian-american frontier during the rebellion of 1837-1838", Canadian Historical Review, vol. 7, núm. 1, marzo de 1926.

-Preston, Richard A., The defense of the undefended border: planning for war in North America, 1867-1939, McGillQueen's University, Montreal, 1977.

-Protest of the irish brigade, $40^{\circ}$ congreso, 2a. sesión, House Executive Document, núm. 157.

-Quinlivan, Patrick y Paul Rose, The fenians in England, 1865-1872: a sense of insecurity, John Calder, Londres, 1982.

-Richardson, James D. (comp.), A compilation of the messages and papers of the presidents, 1789-1902, Bureau of National Literature and Art, Washington, 1907 , vol. 3.

-Senior, Hereward, The last invasion of Canada: the fenian raids, 1866-1870, Dundern Press, Toronto, 1991.

-Shearer C., Ernest, "The Callahan expedition, 1855", Southwestern Historical Quarterly, vol. 54, núm. 4, abril de 1951.

-Shi, David E., "Seward's attempt to annex British Columbia, 1865-1869", Paci- 
fic Historical Review, vol. 47, núm. 2, mayo de 1978.

-Sillanpaa, Leonard, "Death of a liberator, 1838", The Beaver, vol. 70, núm. 1, febrero de 1990 .

-Sloan J., Irving (comp.), Franklin Pierce, 1804-1869: chronology, documents, bibliographicalaids, Oceana Publications, Dobbs Ferry, Nueva York, 1968.

-Slotkin, Richard, The fatal environment: the myth of the frontier in the age of industrialization, Atheneum, Nueva York, 1985.

-Smith, Justin H., Our struggle for the fourteenth colony: Canada and the american revolution, G.P.Putnam's Sons, Nueva York, 1907.

-Somerville, Alexander, Narrative of the fenian invasion of Canada, Joseph Lyght, Toronto, 1866.

-Stacey, C. P., "Fenianism and the rise of national feeling in Canada at the time of confederation", Canadian Historical Review, vol. 12, núm. 3, septiembre de 1931.

Canada and the british army, 1846-1871: a study in the practice of responsible government, University of Toronto, Toronto, 1963.

"Britain's withdrawal from North America, 1864-1871", Canadian Historical Review, vol. 36, septiembre de 1955.

"The fenian troubles and canadian military development", Canadian Defense Quarterly, vol. 13, núm. 3, abril de 1936.

-Stanley, George F. G., "The 1860's and The fighting forces", en J. M. S. Careless y R. Craig Brown (comps.), The Canadians, 1867-1967, St. Martin's Press, Nueva York, 1967.

-Thornhill, Mary Elizabeth, Between friends, Reginald Saunders, Toronto, 1935.

-Trotter, Reginald G., "Some american influences upon the canadian federation movement", Canadian HistoricalReview, vol. 5, núm. 3, septiembre 1924 .

-Turner, Frederick C., La dinámica del nacionalismo mexicano, Editorial Grijalbo, México, 1971.

-Tyler, Ronnie C., "The Callahan expedition of 1855: indians or negroes?", Southwestern Historical Quarterly, vol. 70, núm. 4, abril de 1967.

-Vesey, Maxwell, "When New Brunswick suffered invasion", The Dalhousie Review, vol. 19, núm. 2, julio de 1939.

-Waite, P. B. (comp.), Confederation, 1854-1867, Holt, Rinehart, and Winston of Canada, Toronto, 1972.

-Warner, Donald F., "Drang nach norden: the United States and the Riel rebellion", Mississippi Valley Historical Review, vol. 34, núm. 4, marzo de 1953. The idea of continental union: agitation for the annexation of Canada to the United States, 1849-1893, University of Kentucky, 1960.

-Watt, Alastair, "The case of Alexander McLeod", The Canadian Historical Review, vol. 12, núm. 2, junio de 1931.

-Weinberg, Albert K., Manifest Destiny: a study of nationalist expansionism in american history, Quadrangle Books, Chicago, Ill., 1963.

-Wheeler, Alex E., "Reminiscences of the fenian raid of '66", Annual Report of the York Pioneer and Historical Society, 1912.

\section{HEMEROGRAFÍA}

-The Daily Telegraph (edición extra), Búfalo, Nueva York, 14 de junio de 1966. -New Brunswick Reporter, Fredericton, N. B., 27 de abril de 1866.

-Barrie Examiner (edición extra), 7 de junio de 1866. 


\section{SECUENCIA}

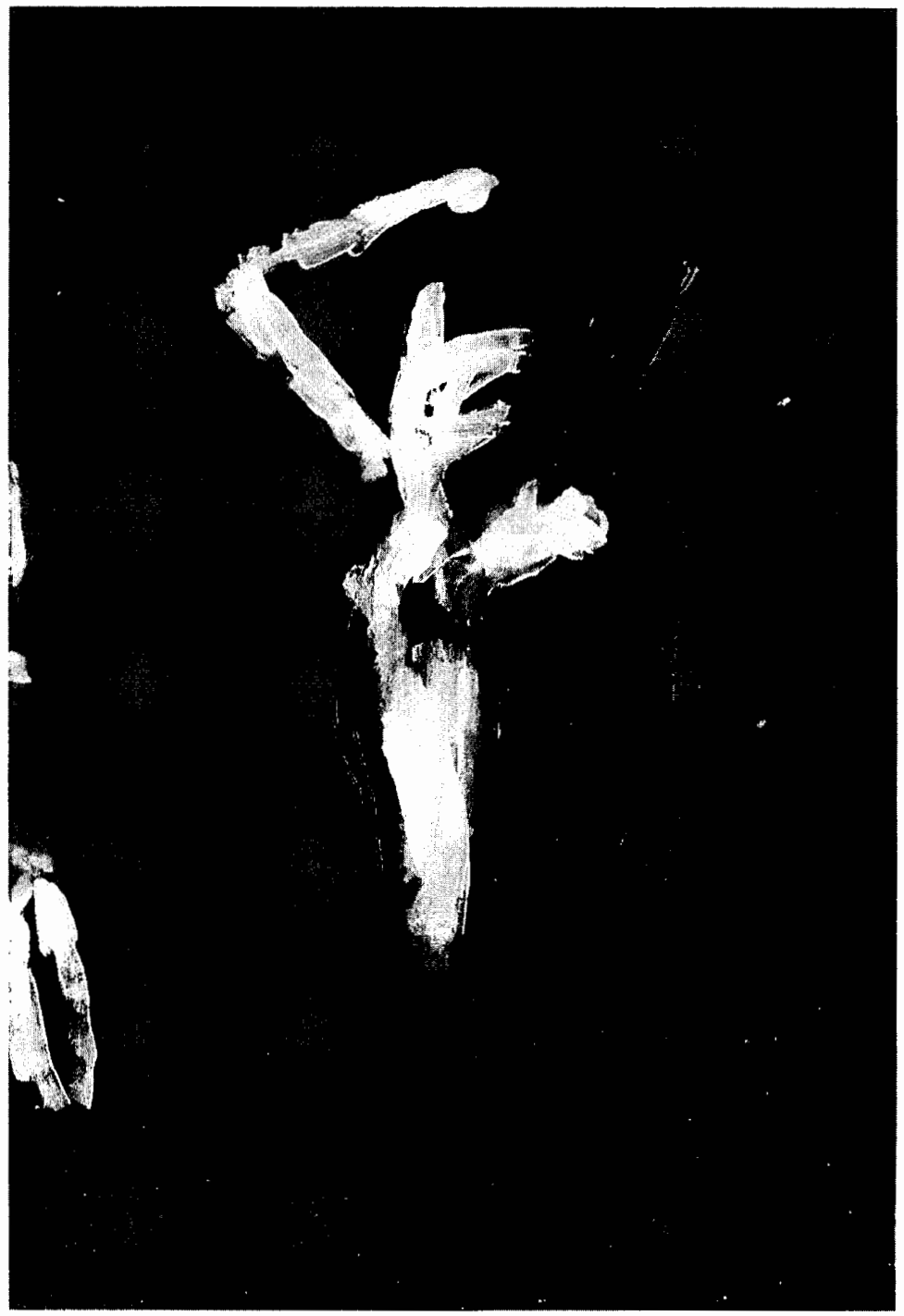

78 